\title{
Characterization of impact pile driving signals during installation of offshore wind turbine foundations
}

Jennifer L. Amaral, James H. Miller, Gopu R. Potty, Kathleen J. Vigness-Raposa, Adam S. Frankel, Ying-Tsong Lin, Arthur E. Newhall, Daniel R. Wilkes, and Alexander N. Gavrilov

Citation: The Journal of the Acoustical Society of America 147, 2323 (2020); doi: 10.1121/10.0001035

View online: https://doi.org/10.1121/10.0001035

View Table of Contents: https://asa.scitation.org/toc/jas/147/4

Published by the Acoustical Society of America

\section{ARTICLES YOU MAY BE INTERESTED IN}

Techniques for distinguishing between impulsive and non-impulsive sound in the context of regulating sound exposure for marine mammals

The Journal of the Acoustical Society of America 147, 2159 (2020); https://doi.org/10.1121/10.0000971

Physical effects of sound exposure from underwater explosions on Pacific sardines (Sardinops sagax) The Journal of the Acoustical Society of America 147, 2383 (2020); https://doi.org/10.1121/10.0001064

Nonlinear time-warping made simple: A step-by-step tutorial on underwater acoustic modal separation with a single hydrophone

The Journal of the Acoustical Society of America 147, 1897 (2020); https://doi.org/10.1121/10.0000937

Estimation of seabed properties and range from vector acoustic observations of underwater ship noise The Journal of the Acoustical Society of America 147, EL345 (2020); https://doi.org/10.1121/10.0001089

Effect of impact pile driving noise on marine mammals: A comparison of different noise exposure criteria The Journal of the Acoustical Society of America 145, 3252 (2019); https://doi.org/10.1121/1.5109387

Effects of multiple exposures to pile driving noise on harbor porpoise hearing during simulated flights—An evaluation tool

The Journal of the Acoustical Society of America 147, 685 (2020); https://doi.org/10.1121/10.0000595

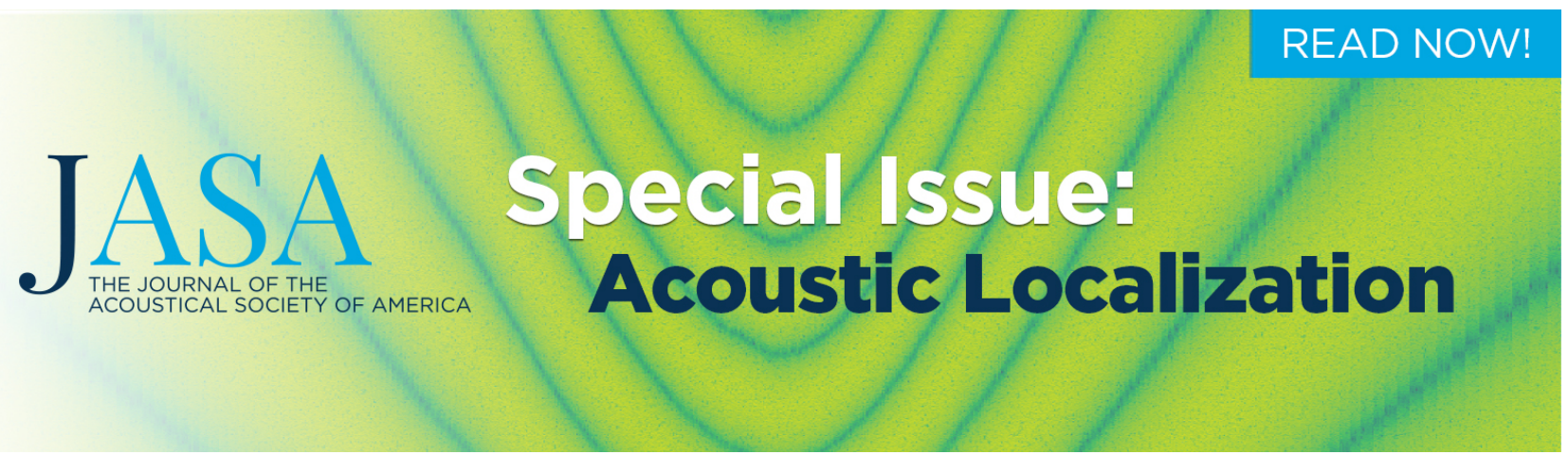




\title{
Characterization of impact pile driving signals during installation of offshore wind turbine foundations
}

\author{
Jennifer L. Amaral, ${ }^{1, a)}$ James H. Miller, ${ }^{1}$ Gopu R. Potty, ${ }^{1}$ Kathleen J. Vigness-Raposa, ${ }^{2}$ Adam S. Frankel, ${ }^{2}$ \\ Ying-Tsong Lin, ${ }^{3}$ Arthur E. Newhall, ${ }^{3}$ Daniel R. Wilkes, ${ }^{4}$ and Alexander N. Gavrilov ${ }^{4}$ \\ ${ }^{1}$ Department of Ocean Engineering, University of Rhode Island, Narragansett, Rhode Island 02882, USA \\ ${ }^{2}$ Marine Acoustics, Inc, 2 Corporate Place, Suite 105, Middletown, Rhode Island 02842, USA \\ ${ }^{3}$ Applied Ocean Physics and Engineering, Woods Hole Oceanographic Institution, Woods Hole, Massachusetts 02543, USA \\ ${ }^{4}$ Centre for Marine Science and Technology, School of Earth and Planetary Sciences, Curtin University, GPO Box U1987, Perth, \\ Western Australia 6845, Australia
}

\begin{abstract}
:
Impact pile driving creates intense, impulsive sound that radiates into the surrounding environment. Piles driven vertically into the seabed generate an azimuthally symmetric underwater sound field whereas piles driven on an angle will generate an azimuthally dependent sound field. Measurements were made during pile driving of raked piles to secure jacket foundation structures to the seabed in waters off the northeastern coast of the U.S. at ranges between $500 \mathrm{~m}$ and $15 \mathrm{~km}$. These measurements were analyzed to investigate variations in rise time, decay time, pulse duration, kurtosis, and sound received levels as a function of range and azimuth. Variations in the radiated sound field along opposing azimuths resulted in differences in measured sound exposure levels of up to $10 \mathrm{~dB}$ and greater due to the pile rake as the sound propagated in range. The raked pile configuration was modeled using an equivalent axisymmetric FEM model to describe the azimuthally dependent measured sound fields. Comparable sound level differences in the model results confirmed that the azimuthal discrepancy observed in the measured data was due to the inclination of the pile being driven relative to the receiver. (C) 2020 Acoustical Society of America. https://doi.org/10.1121/10.0001035
\end{abstract}

(Received 23 November 2019; revised 19 March 2020; accepted 19 March 2020; published online 17 April 2020)

[Editor: Arthur N. Popper]

Pages: 2323-2333

\section{INTRODUCTION}

Impact pile driving creates intense sound that radiates into the environment and propagates through the air, water, and sediment. Characteristics of the resulting sound radiation are strongly dependent on the pile configuration, hammer impact energy, and environmental properties at the pile location and in the surrounding area. With the global development of offshore wind farms, there have been increased opportunities to measure the underwater sound fields generated during pile driving activities in different environments and of varying pile diameters (Bailey et al., 2010; De Jong and Ainslie, 2008; Göttsche et al., 2015; Norro et al., 2013; Robinson et al., 2012). The majority of these measurements have been of monopiles or other vertically driven piles, while few measurements of raked (angled) piles have been described (Martin and Barclay, 2019; Wilkes and Gavrilov, 2017).

The dominant source of sound that is generated during pile driving is due to the hammer impact. For a hollow steel pile, the resulting sound field is comprised of a series of Mach waves (Dahl and Dall'Osto, 2017; Dahl and Reinhall, 2013; Reinhall and Dahl, 2011; Zampolli et al., 2013). The

a) Also at: Marine Acoustics, Inc, 2 Corporate Place, Suite 105, Middletown, Rhode Island 02842, USA. Electronic mail: jennifer.amaral@marineacoustics.com hammer strike and resulting compression wave cause the pile to bulge outward and deform, due to the Poisson effect. This physical deformation propagates down the pile and acts as a moving sound source. The resulting acoustic field consists of a series of downward- and upward-propagating axisymmetric Mach wave cones (Kim et al., 2013; Reinhall and Dahl, 2011).

Reinhall and Dahl (2011) and Kim et al. (2013) described the propagation of these Mach wave cones from vertically driven piles, and Wilkes and Gavrilov (2017) modeled the Mach cone radiating from an angled pile. The angle of the initial Mach cone relative to the pile axis is dependent on the ratio of the sound speed in water $\left(\mathrm{c}_{w}\right)$ to the propagation speed of the radial deformation down the pile $\left(\mathrm{c}_{p}\right)$, which is close to the compressional wave speed in steel [Eq. (1)] (Reinhall and Dahl, 2011),

$$
\theta=\sin ^{-1}\left(c_{w} / c_{p}\right) \text {. }
$$

Raked piles are common in infrastructure projects because of their increased resistance to lateral loads. Due to the non-axisymmetric geometry of the pile relative to the seabed, raked piles are expected to radiate underwater sound with an azimuthal dependence. Wilkes and Gavrilov (2017) and Martin and Barclay (2019) demonstrated that sound radiation from a raked pile is significantly different at various azimuths from the pile. Measured sound exposure levels 
(SELs) radiated by piles raked at an angle of $14^{\circ}$ to the vertical and inclined toward the receiver were $10 \mathrm{~dB}$ lower at distances of $1.2-1.5 \mathrm{~km}$ than those radiated from piles inclined away from the receiver (Wilkes and Gavrilov, 2017).

The sounds generated from impact pile driving are described as impulsive, which exhibit physical characteristics at the source that make them potentially more injurious to marine mammals and fishes as compared to nonimpulsive sounds (Popper et al., 2014; Southall et al., 2019). Impulsive signals are defined as short-duration broadband sounds that consist of a peak sound pressure amplitude with a rapid rise time to the peak followed by a decay (National Marine Fisheries Service, 2018). An impulsive signal may undergo changes due to propagation effects that could result in the signal being perceived by animals as non-impulsive at some other range (National Marine Fisheries Service, 2018; Southall et al., 2007; Southall et al., 2019). A range at which a signal might transition from being considered impulsive to non-impulsive was briefly identified as $3 \mathrm{~km}$ in draft sound exposure guidance, but was omitted from the final guidance as more research is needed to determine this range (National Marine Fisheries Service, 2015). The consideration of a transition range is important when applying acoustic exposure guidance as Southall et al. (2019) recommends that the signal characteristics expected to be received by the animal rather than those at the source dictate the exposure guidance used (impulsive or non-impulsive). Since propagation is dependent on the local environmental conditions (sound speed, bottom sediment properties, water depth, surface roughness, etc.), defining a definitive distance that would be valid for all propagation environments is not straightforward. Also, what measurable signal characteristic could be used to determine when a signal has undergone that transition?

One such metric could be kurtosis, which is a statistical measure that represents the impulsiveness of an event (National Marine Fisheries Service, 2018). According to Hamernik et al. (2003) and Lei et al. (1994), the kurtosis of a signal, in addition to an energy metric, is an important variable in determining hazards to hearing and is a good predictor of the relative magnitude of acoustic trauma between signals that differ in impulsiveness. Impulsive signals with high kurtosis and high instantaneous peak sound pressure may be more injurious to certain mammals (Southall et al., 2007). Rise time is another relevant metric to describe the temporal structure of the signal that could be tied to the impact a sound will have (Henderson and Hamernik, 1986; Laughlin, 2005). Studies are ongoing to determine the most appropriate metric, but the onset of damage to hearing for impulsive sounds may be more appropriately measured by the rise time of a signal as opposed to the kurtosis (Popper et al., 2006). Additionally, a combination of the rise time, ratio of peak pressure to pulse duration, pulse duration, and crest factor could all be metrics used to evaluate a change in the impulsive nature of a signal over range (Hastie et al., 2019).

This study will present measurements collected from the installation of raked piles in coastal waters at the Block
Island Wind Farm (BIWF) off the coast of Block Island, Rhode Island, USA. Steel piles were driven into the seabed to pin the jacket-type wind turbine foundation structures at BIWF. These types of foundations were used due to their suitability in deeper waters relative to other foundations currently available. Jacket foundations have been used extensively in the offshore oil and gas industry and were a costeffective choice for the BIWF based on the robust supply chain in the U.S. for the construction and installation of these foundations. Based on these factors, the jacket foundation was the preferred choice for the BIWF (Tetra Tech, 2012).

The piles driven at the BIWF were raked at an angle of $13.27^{\circ}$ to the vertical. This rake resulted in the incident angle of the radiated Mach wave on the seabed changing based on azimuth. The Mach wave generated with each hammer strike is radiated out from the pile at an angle typically around $18^{\circ}$ depending on the exact ratio of the speed of sound in steel and the surrounding water (Dahl and Dall'Osto, 2017; MacGillivray, 2018). The similarities between the pile rake and Mach wave angle resulted in the sound radiating from the pile axis in the direction of the pile inclination to be directed more towards the seafloor as opposed to the sound in the opposite direction, which was directed near horizontal into the water column. The steeper the incident angle of the Mach wave to the seafloor, the more energy was absorbed by the seafloor (HDR, 2018). The effect of pile rake on the resulting sound field was evident in the received signals. This sound radiation pattern is demonstrated in Wilkes and Gavrilov (2017) where the pile orientation is similar to that of the BIWF.

The objective of this study was to describe the measurements collected of pile driving at the BIWF as a function of range, azimuth, and strike energy. The variation in the rise time, decay time, pulse duration, and kurtosis of the signals was investigated to determine if there was supporting evidence to define a range at which the signal transitioned from impulsive to non-impulsive. Martin and Barclay (2019) presented measurements of pile driving at BIWF from stationary systems and analyzed the data using linear mixed models based on damped cylindrical spreading to conclude that the variability in the received level was largely due to the pile rake. The study described in this manuscript utilizes a finite element model to investigate the variation observed in the data from both towed and stationary systems to further explain the conclusion that the dominant source of the sound level variation was the inclination of the pile relative to the receiver.

The paper is organized in the following manner. Section II describes the study location along with the measurement equipment, details of the turbine foundations and piling activity, and analysis methods. Section III presents the data collected and the variations observed in the measured sound levels due to the pile rake and range. The pulse duration and kurtosis of the pile driving signals are also discussed. Section IV includes a discussion of the observations as compared to modeled results. Section V presents the main conclusions of this study. 


\section{OBSERVATION METHODS}

The location of the following study was the Block Island Wind Farm, which is the first offshore wind farm in U.S. waters. It is a $30-\mathrm{MW}$ wind farm that is comprised of five 6-MW turbines located three miles southeast of Block Island, Rhode Island, in water depths of approximately 30 meters. The U.S. Bureau of Ocean Energy Management (BOEM) funded a project to study the development and operation of this wind farm. The goal of the project was to collect real-time measurements of the construction and operation activities from the first federally permitted offshore wind farm in U.S. coastal waters to allow for more accurate assessments of the environmental effects and inform development of appropriate mitigation measures.

The University of Rhode Island (URI), Marine Acoustics, Inc. (MAI), and Woods Hole Oceanographic Institution (WHOI) were funded under this project to investigate the acoustic pressure and particle velocity associated with the construction and operation of the wind turbines. Various stationary and towed acoustic measurement systems were deployed (Fig. 1) in the vicinity of the BIWF. The measurements collected on the stationary and towed systems during the pile driving activities that occurred between September and October of 2015 were analyzed and will be discussed in this paper. Measurements were made at ranges between $500 \mathrm{~m}$ and $15 \mathrm{~km}$ from the wind turbine foundations.

\section{A. Measurement equipment}

Stationary measurement systems of two vertical line arrays (VLAs) and a bottom-deployed geophysical sled were deployed for 24 days between October and November 2015. Pile driving on seven separate days was recorded during this deployment. Data were recorded continuously on sensors connected to Several Hydrophone Receive Units (SHRUs) developed and maintained by WHOI. All of the sensors were recording at a sampling rate of approximately $10 \mathrm{kHz}$ for the duration of the deployment.

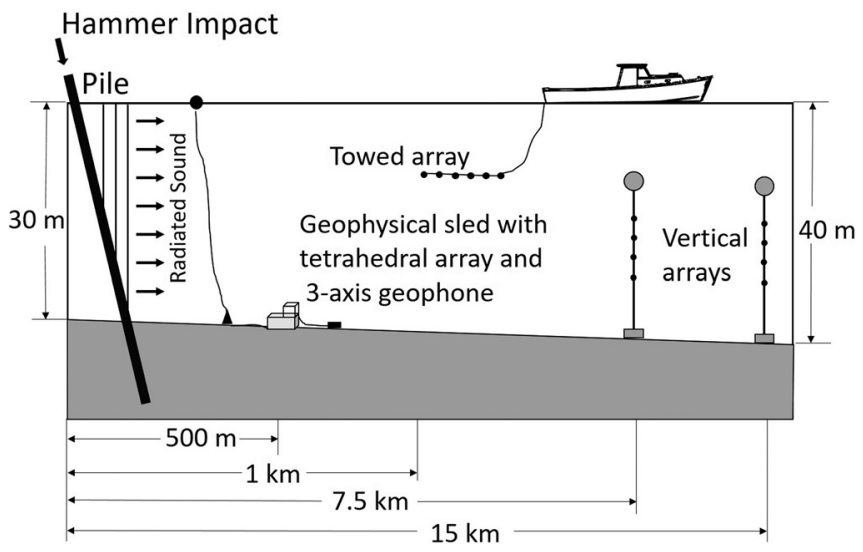

FIG. 1. Simplified schematic of all the measurement systems deployed by URI, MAI, and WHOI to measure the underwater sound and particle velocity generated by the pile driving associated with the Block Island Wind Farm (BIWF).
A geophysical sled that included a four-hydrophone tetrahedral array and a geophone sensor package was deployed $500 \mathrm{~m}$ from the foundation of the Wind Turbine Generator (WTG) 3 in roughly $26 \mathrm{~m}$ of water. The sensor package consisted of a three-axis geophone and a low sensitivity hydrophone. Acoustic particle velocity was measured in the water column and on the seabed using the tetrahedral array and the geophone data. The hydrophones used in the array were the HTI-94-SSQ model from High Tech, Inc., with a sensitivity of $-204 \mathrm{~dB}$ re $1 \mathrm{~V} / \mu \mathrm{Pa}$. They were spaced $0.5 \mathrm{~m}$ apart in the array and deployed at the seafloor.

The two vertical line arrays each consisted of four HTI-94-SSQ hydrophones spaced $5 \mathrm{~m}$ apart at water depths between 20 and $40 \mathrm{~m}$. Two different amplifier gains were applied to the signals recorded on the array. The sensitivity of these hydrophones was $-170 \mathrm{~dB}$ re $1 \mathrm{~V} / \mu \mathrm{Pa}$. One of the amplifier gain settings resulted in the pressure signals being clipped, and therefore, these data were eliminated from the analysis and only the non-clipped data were used. These arrays were moored 7.5 and $15 \mathrm{~km}$ from the WTG 3 location and were both in roughly $40 \mathrm{~m}$ of water (Fig. 2).

In addition to the stationary sensors, a passive towed array was deployed by MAI on two separate days from the $\mathrm{R} / \mathrm{V}$ Shanna Rose during pile driving to measure the received sound levels with range from the foundation. The array consisted of eight elements irregularly spaced over its $120 \mathrm{~m}$ length. Approximately $50 \mathrm{~m}$ of lead-in cable was deployed to keep the array at depths between 6 and $12 \mathrm{~m}$ during the pile

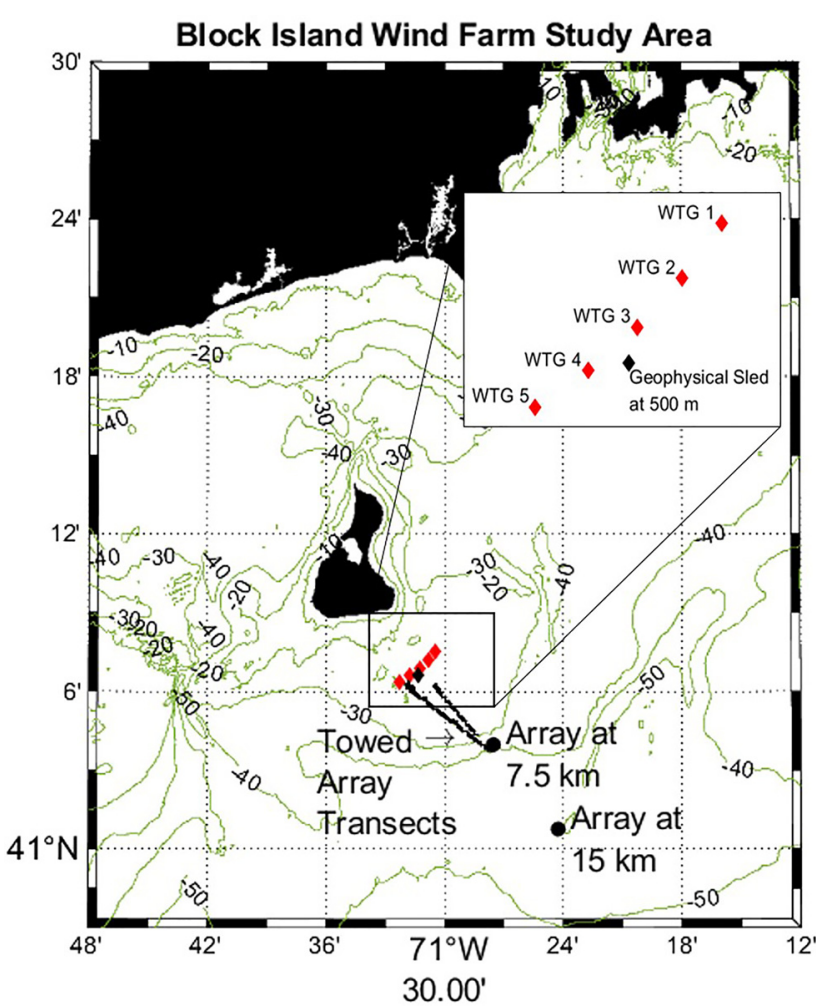

FIG. 2. (Color online) Location of the vertical line arrays at $7.5 \mathrm{~km}$ and $15 \mathrm{~km}$ from the Wind Turbine Generator (WTG) foundations and the geophysical sled at $500 \mathrm{~m}$. The two towed array transects are also shown. Bottom depth contours are indicated in meters. 
driving. Sea Bird SBE39 temperature and pressure sensors were placed along the array cable to estimate the shape of the array in the water column during deployment.

When towing the array, the vessel maintained a linear course away from the foundations at a speed of approximately $1.5 \mathrm{~m} / \mathrm{s}$ out to distances of 6 and $8 \mathrm{~km}$ on the two days. The maximum distance was dictated by the duration of the pile driving activity on both days. Data at ranges greater than $5 \mathrm{~km}$ were eliminated from this analysis due to decreasing signal-to-noise ratio in the recorded data. The noise was due to flow-induced turbulent pressure fluctuations on the hydrophones. The analog output from the array was low pass filtered at $30 \mathrm{kHz}$ and amplified with an Alligator Technologies SCS-820 filter board. A National Instruments PCI-6071E card digitized the filtered data at a sampling rate of $64 \mathrm{kHz}$. Amplifier gains were applied during data acquisition to increase the signal amplitude as the range of the array from the pile driving activity increased. Data were collected using RAVEN Pro v 1.4 (www.birds.cornell.edu/raven) and saved in consecutive $30 \mathrm{~s}$ files for post-processing.

\section{B. Turbine foundations}

The jacket foundations at BIWF consisted of hollow steel tubular members joined together in a lattice structure, which sits on the seabed to support the WTG. The legs of the jacket foundation were raked at an angle of $13.27^{\circ}$ to the vertical. Each foundation required cylindrical, steel piles, split into multiple sections, to be impact driven through the legs at the four corners of the structure to secure it to the seabed (Fig. 3). The diameter of the driven piles was $152 \mathrm{~cm}$ with a wall thickness of $4.4 \mathrm{~cm}$. The piles were driven to a depth of up to $76.2 \mathrm{~m}$ below the mudline (water-sediment interface) (Tetra Tech, 2012).

Each foundation had a total of four legs that will be referred to as A1, A2, B1, and B2. Each leg of the foundation required a total of three pile sections, which will be referred to as P1, P2, and P3. Figure 4 shows a top-down schematic

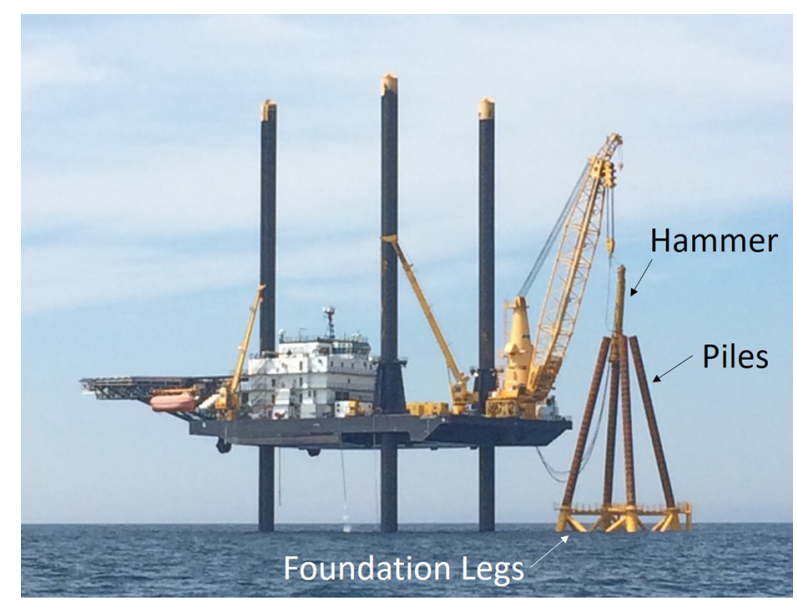

FIG. 3. (Color online) Jacket foundation in the water with a pile section inserted into each leg at an angle of $13.27^{\circ}$ relative to the vertical and the hammer positioned on one of the piles.

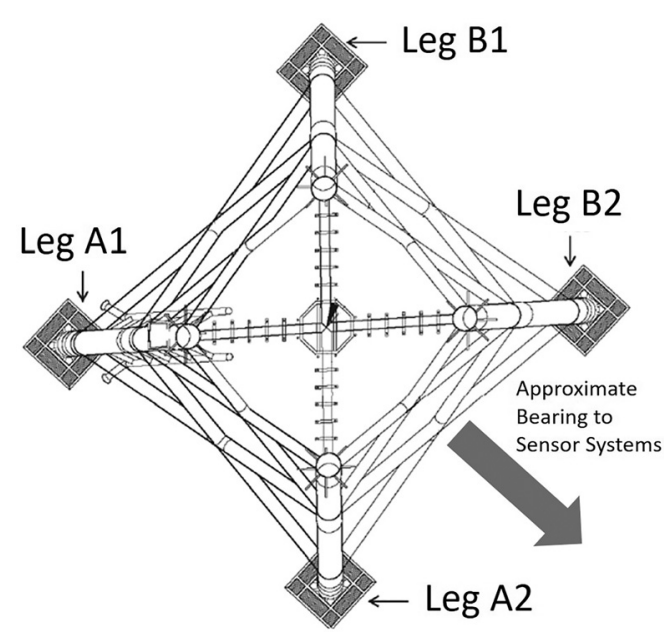

FIG. 4. Top-down schematic of the jacket foundation showing orientation of the four legs and the direction of the deployed measurement systems in relation to the foundation (Tetra Tech and JASCO, 2015).

of the wind turbine foundation showing the orientation of the four legs and the general direction to the deployed measurement systems in relation to the foundation.

The measurement systems deployed during the BIWF construction captured pile driving on various legs and pile sections. No mitigation measures, such as bubble curtains, were employed at BIWF. Due to the location of the measurement systems relative to the foundation, the sound radiated from the piling of legs $\mathrm{A} 1$ and $\mathrm{B} 1$ was directed toward the seafloor and the sound radiated from the piling of legs $\mathrm{A} 2$ and $\mathrm{B} 2$ was directed near horizontal into the water column. The effect of pile rake on the resulting sound field was evident in the received signals, with the sound levels from the $\mathrm{A} 2$ and $\mathrm{B} 2$ legs being higher than those from the A1 and B1 legs.

\section{Data analysis}

Custom analysis scripts were written in MATLAB R2019a (www.mathworks.com) to detect the pile driving signals and evaluate various metrics of each recorded hammer strike encompassing the entire recorded frequency range of the signals. The upper limit of the frequency content in the signals recorded on the stationary systems was just under $5 \mathrm{kHz}$ as compared to an upper limit of $30 \mathrm{kHz}$ for the towed array measurements. The peak sound pressure level $\left(\mathrm{SPL}_{p k}\right)$, SEL, pulse duration, rise time, decay time, and kurtosis of each individual hammer strike signal were calculated. These measurements were correlated with the strike energy of the hammer to investigate dependence on the initial strike energy and pile orientation. The towed array data were also correlated with distance to investigate the range dependencies of these metrics.

The sound metrics were calculated using the following equations, where $p(t)$ is the sound pressure time series recorded at the receiver.

Peak sound pressure level [dB re $1 \mu \mathrm{Pa}]$ :

$$
S P L_{p k}=20 \log _{10} \max (|p(t)|) .
$$


The time interval that contains $90 \%$ of the sound energy is a meaningful definition of pulse duration for impulsive signals. This energy percentage is defined in the International Organization for Standardization (ISO) 18406 (2017b) for the purpose of defining the pulse duration of hammer strikes during impact pile driving. This duration is bounded by the times when the cumulative signal energy exceeds $5 \%$ of the total signal energy and ends when it reaches 95\% (Southall et al., 2007).

The rise time of a signal is the time it takes for a signal to rise from $10 \%$ to $90 \%$ of its maximum absolute value of sound pressure, as defined in ISO 10843 (1997). The decay time of a signal was calculated as the time it takes for the signal to decay to $95 \%$ of the cumulative signal energy from the time of peak sound pressure.

SEL [dB re $\left.1 \mu \mathrm{Pa}^{2} \mathrm{~s}\right]$ : The pulse duration (T) containing $90 \%$ of the pulse energy was used to calculate the single strike SEL based on Eq. (3). All SEL values reported in this paper are single strike values,

$$
S E L=10 \log _{10} \int_{T} p(t)^{2} d t .
$$

Kurtosis is a dimensionless statistical measure of a probability distribution that can be used to describe the shape of an amplitude distribution (Southall et al., 2007). It is the ratio of the fourth central moment divided by the square of the variance of the sound pressure time series over a specified time interval ( $t_{1}$ to $\left.t_{2}\right)$ defined according to Eq. 4, where $\bar{p}$ is the mean sound pressure within that time interval. This definition is consistent with that presented in ISO 18405 (2017a):

$$
\text { Kurtosis }=\frac{\mu_{4}}{\mu_{2}^{2}}=\frac{1 /\left(t_{2}-t_{1}\right) \sum_{t_{1}}^{t_{2}}(p(t)-\bar{p})^{4}}{\left(1 /\left(t_{2}-t_{1}\right) \sum_{t_{1}}^{t_{2}}(p(t)-\bar{p})^{2}\right)^{2}} .
$$

While kurtosis can help describe impulsive signals, it is sensitive to variables such as the level and duration of impulses, the temporal structure of the noise, and the duration of the noise sample over which the kurtosis is calculated. Hamernik et al. (2003) reported that the kurtosis stabilized for windows greater than $30 \mathrm{~s}$, Lei et al. (1994) calculated kurtosis over a time window of $256 \mathrm{~s}$, Martin (2019) recommended calculating kurtosis over a one-minute window, Kastelein et al. (2017) used a one-second time window, and Erdreich (1986) used a time window of $11 \mathrm{~s}$. The duration over which to calculate kurtosis is arbitrary, which is highlighted by the varying time duration in the referenced studies. If interest is in marine mammal perception of a certain sound, the time duration could be chosen based on the physiological factors of hearing for a species of interest (Erdreich, 1986).

The purpose of calculating kurtosis on the BIWF data was to use it as a measure of impulsiveness over range based on the temporal structure of the signal of each individual strike. Therefore, the kurtosis was calculated for each hammer strike using a one-second window that encompassed the peak in the signal. The window was defined as $0.1 \mathrm{~s}$ before to $0.9 \mathrm{~s}$ after the time of the peak. This time window was chosen to contain only one hammer strike.

\section{RESULTS}

The towed array and stationary measurement systems recorded pile driving events along a constant bearing from the jacket foundation, but at varying orientations relative to the raked piles. An event was classified as the pile driving installation of a single pile section. On the stationary vertical line array systems, the installation of sections P2 and P3 for the WTG 1 and 4 foundation legs were recorded, which was a total of 16 pile driving events. On the towed array, two complete pile driving events were recorded for the installation of P1 A2 on WTG 3 and of P1 A1 on WTG 5. The measured sound levels collected on the towed array and vertical line array measurement systems are presented.

All of these measurements were made during the beginning of September through mid-October. While there are seasonal differences in the water temperature and salinity that affect the underwater sound propagation, the time frame of these measurements is concentrated in one season and therefore not expected to result in large differences in the sound propagation. The temperature profiles taken on the days of the towed array transects showed a downward refracting temperature profile that was similar between the two days. Had the pile driving occurred in the winter season, the received SELs at ranges greater than $6 \mathrm{~km}$ could have been close to $8 \mathrm{~dB}$ higher due to lower water temperature and a more isovelocity sound speed profile (Lin et al., 2019).

\section{A. Stationary measurements}

The data presented in this paper are from one channel of the vertical line array at $7.5 \mathrm{~km}$ from the pile driving activity. They are representative of the data collected on the other channels with similar gain and on the vertical line array at $15 \mathrm{~km}$. This hydrophone was at a depth of $25 \mathrm{~m}$. Figure 5 shows the time series of one day of pile driving activity for the installation of section P2 for all four legs on WTG 1 . The sound pressure amplitudes of the received signals for the different events are shown, with the amplitudes of events recorded from legs B2 and A2 being much higher than those from legs $\mathrm{A} 1$ and B1. These higher amplitudes resulted in the measured sound pressure level (SPL) $)_{p k}$ and SEL for these events being higher than those for the A1 and B1 events (upper two plots of Fig. 6).

To investigate the cause of the differences in received sound pressure amplitudes in Fig. 5, the strike energy of the individual hammer strikes was correlated to the measured received levels. The pile driving logs were obtained from Menck GmbH (www.menck.com), who was responsible for the pile driving installation for the BIWF. The time records 


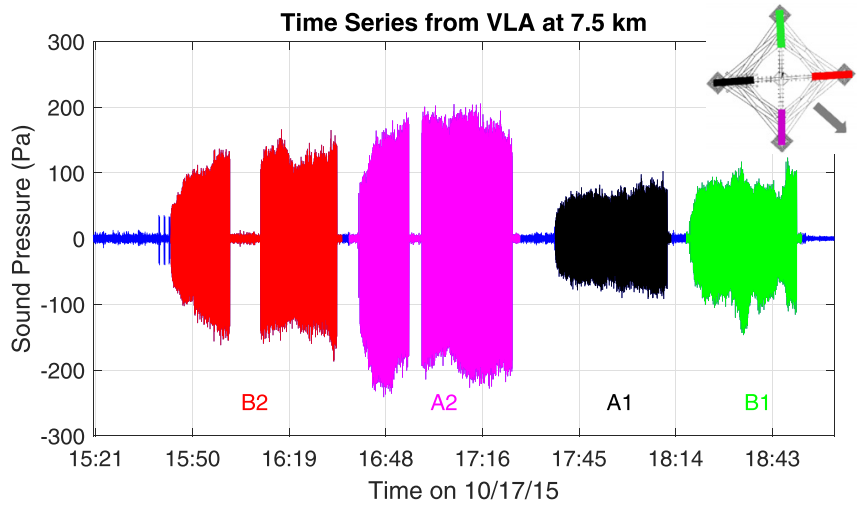

FIG. 5. (Color online) Time series example of one day of pile driving on WTG 1 recorded on the array at $7.5 \mathrm{~km}$ at a depth of $25 \mathrm{~m}$. The amplitude of the measured pressure signals from the hammer strikes on the B2 and A2 legs are larger than those on the $\mathrm{A} 1$ and $\mathrm{B} 1$ legs.

from Menck and the deployed systems were aligned so that the hammer energy associated with each recorded strike could be compared. This comparison showed that although the measured received sound levels for the driving of legs
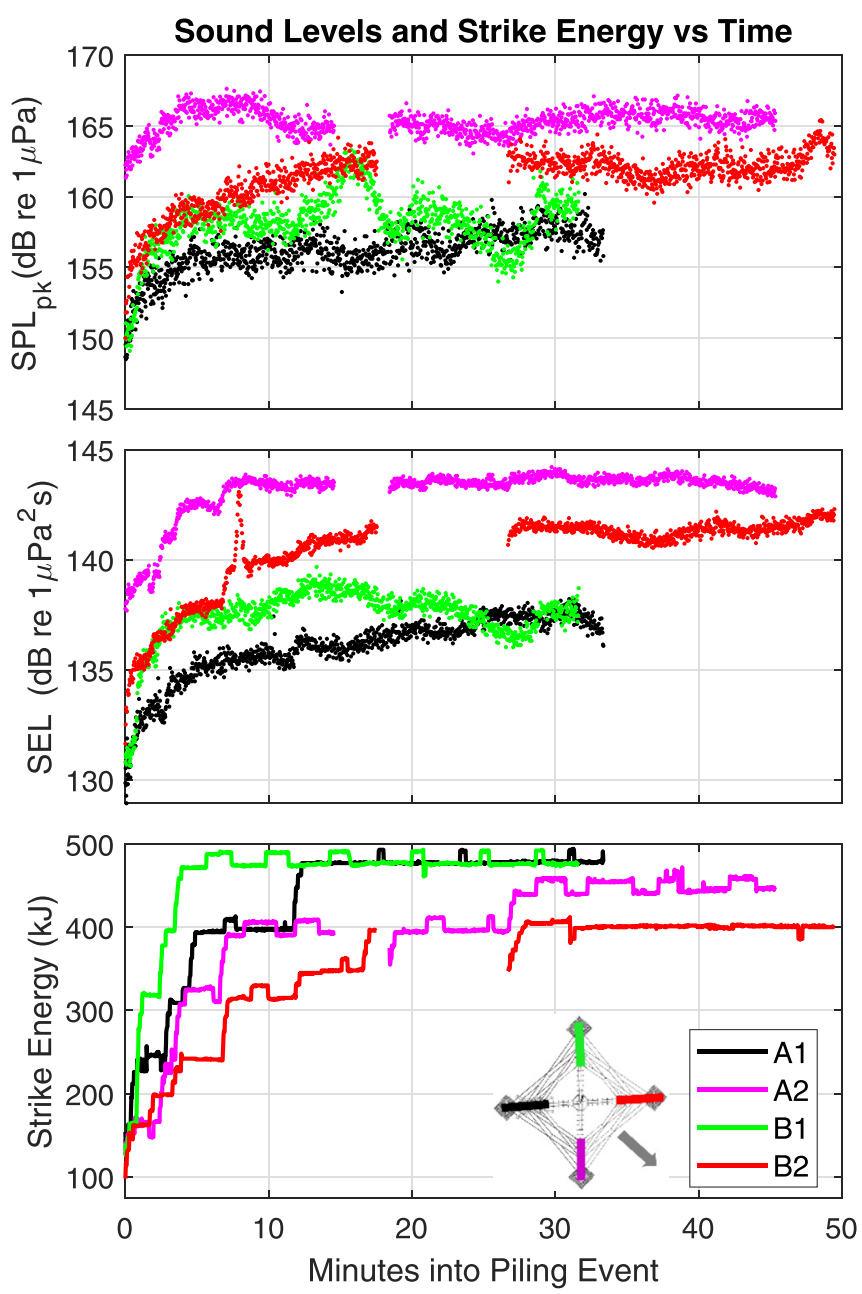

FIG. 6. (Color online) Received $\mathrm{SPL}_{p k}$ (top), SEL (middle), and corresponding energy (bottom) of the pile driving strikes presented in Fig. 5. While the strike energy was higher for the piling of legs A1 and B1, the received sound levels were lower for these legs than for legs A2 and B2.
$\mathrm{A} 2$ and B2 were consistently higher, the strike energies used to drive these legs were lower than those used for the driving of legs A1 and B1 (bottom plot in Fig. 6).

In this example, the duration of the piling events for legs A1 and B1 was shorter than the piling of legs A2 and B2. The length of the pile section being driven was the same for all four legs, but the higher strike energy for the duration of the piling for the A1 and B1 legs resulted in the pile reaching depth in a shorter amount of time. During the BIWF construction, all pile driving activities had to be completed during daylight hours, ending $30 \mathrm{~min}$ prior to dusk (Tetra Tech, 2012). It is a reasonable assumption that since legs $\mathrm{A} 1$ and $\mathrm{B} 1$ were driven last the hammer operators increased the strike energy to ensure the complete installation of these legs before dark. Regardless of the reasoning behind the shorter duration and higher intensity pile driving, the received sound levels were still less than those from legs $\mathrm{A} 2$ and $\mathrm{B} 2$.

The measured sound levels from the hammer strikes on legs $\mathrm{A} 2$ and $\mathrm{B} 2$ were consistently higher than those on legs $\mathrm{A} 1$ and B1, independent of strike energy during all of the recorded pile driving events (Fig. 7). This led to the determination that the dominant factor influencing the received sound levels from legs at different azimuths was the inclination of the pile relative to the receiver. Findings presented in Wilkes and Gavrilov (2017) showed a roughly $10 \mathrm{~dB}$ difference in SELs received from piles inclined in opposite directions.

\section{B. Towed array measurements}

All analysis was performed using the towed array hydrophone farthest from the towing vessel and also the deepest in the water column. It was towed at a depth of 10-12 m during

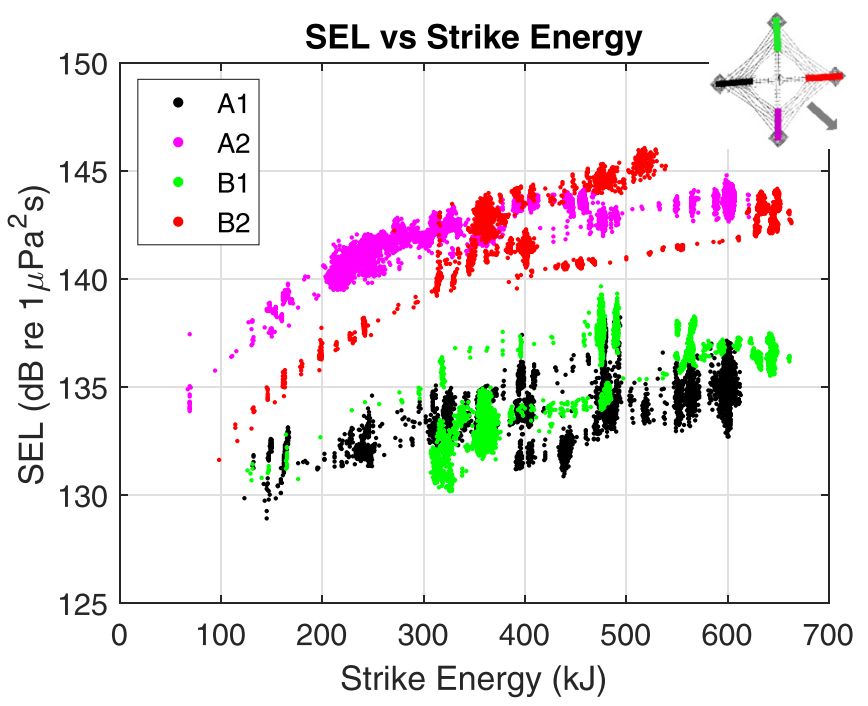

FIG. 7. (Color online) SEL versus strike energy for each recorded hammer strike from all 16 measured piling events. The received levels for the piling of legs A2 and B2 were consistently higher than those for legs A1 and B1, independent of strike energy. This supports the determination that the dominant factor influencing the received sound levels from different legs is the inclination of the pile to the receiver. 
the events. The effect that distance had on the received sound levels and signal characteristics will be presented.

Figure 8 shows a comparison of the received sound levels for both of the pile driving events recorded with the towed array. These sound levels have been adjusted to remove the effect of the strike energy by subtracting $10 \log _{10}$ (StrikeEnergy) from the measured levels, where the strike energy was in kilojoules $(\mathrm{kJ})$. This was done to compare the received levels in relation to the distance from the piling event independent of strike energy. Then the levels were normalized by the maximum received sound level to produce the comparison seen in Fig. 8. The measured SPL $p k$ and SEL from the piling of leg A2 were consistently higher than that of leg A1 over the entire towed array transect, which is thought to be due to the orientation of the leg relative to the receiver.

\section{Variations in signal characteristics}

The rise and decay time of the signal recorded on the towed array from each hammer strike was calculated and plotted versus distance to investigate its dependence on range from the foundation (Fig. 9). Only signals with a high enough signal-to-noise ratio to allow for reliable calculation of the rise time were included in the following comparisons.
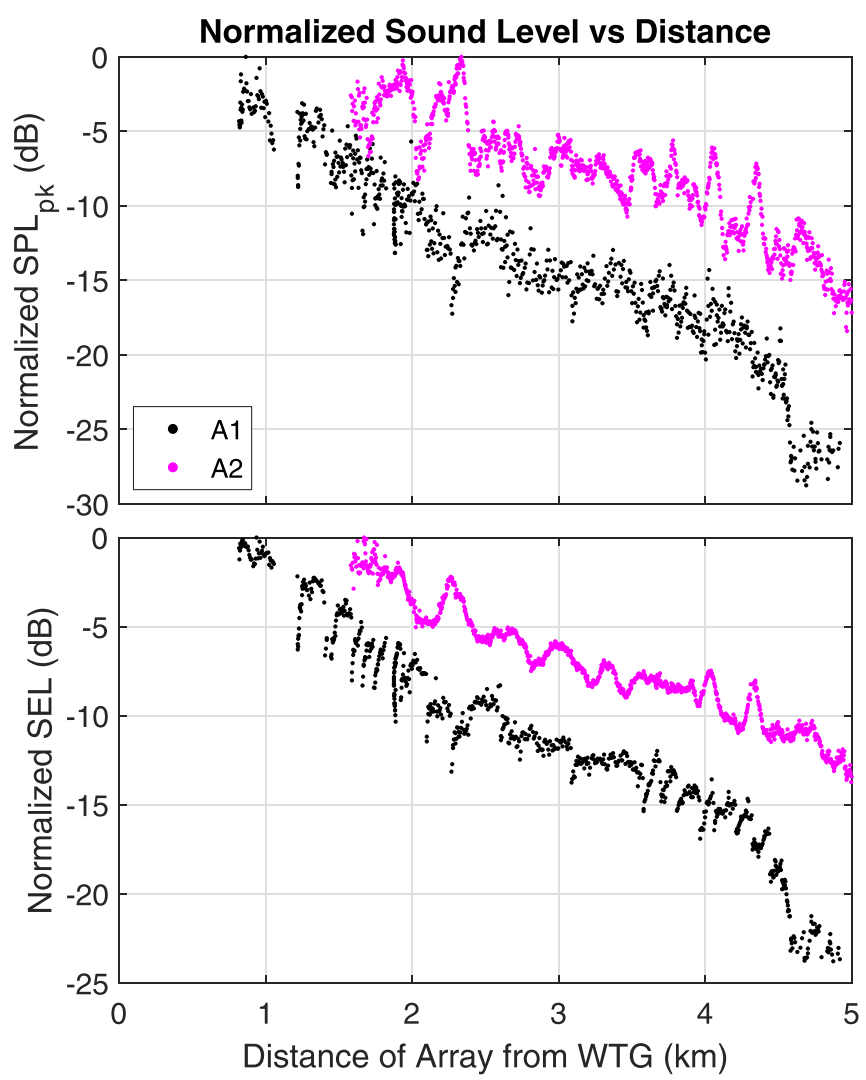

FIG. 8. (Color online) Normalized $\mathrm{SPL}_{p k}$ (top) and SEL (bottom) versus distance for each hammer strike measured on the towed array for the pile driving of the A2 and A1 legs. Levels have been adjusted to remove the effect of strike energy and normalized to highlight the difference in received levels between the two piling events. The difference increases to around $10 \mathrm{~dB}$ by $5 \mathrm{~km}$.
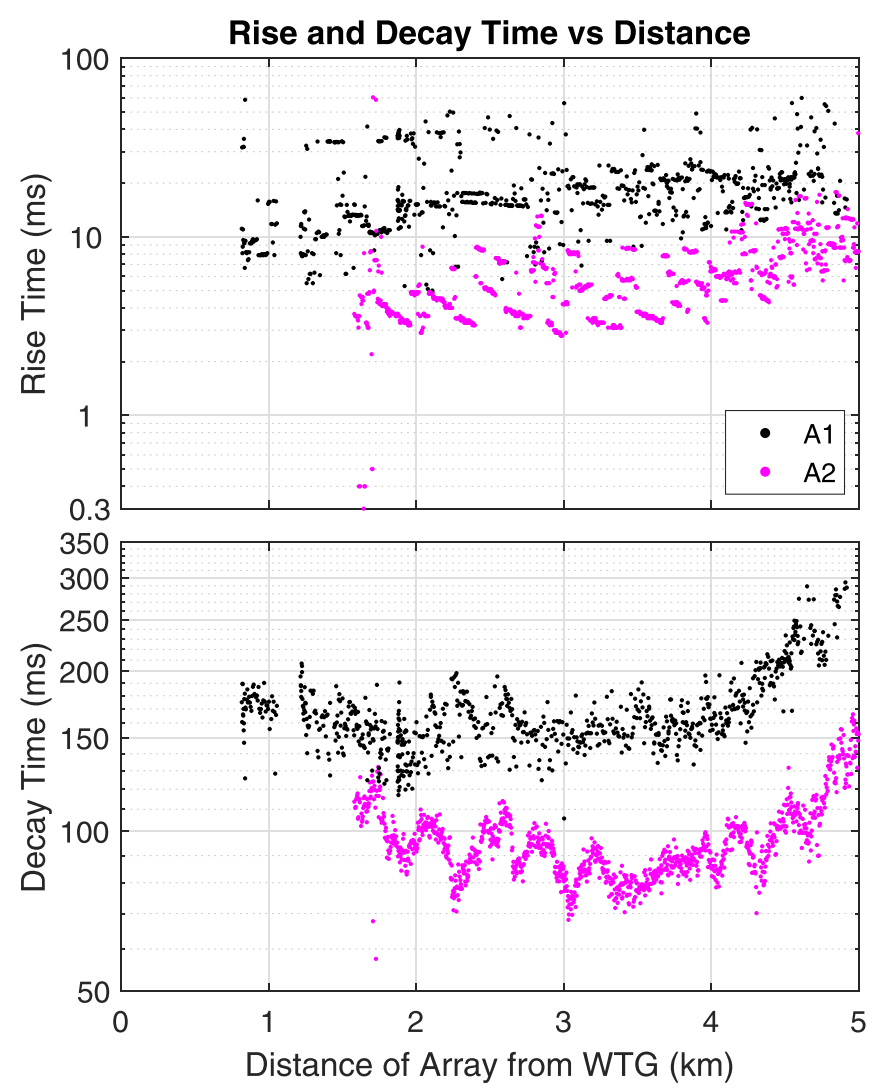

FIG. 9. (Color online) Rise time (top) and decay time (bottom) versus distance for each hammer strike measured on the towed array for the pile driving of the A2 and A1 legs. The signal from the A1 leg had longer rise and decay times than the signals recorded from the A2 leg.

The signals from the A1 leg had longer rise and decay times over range than those from the A2 leg. These differences are thought to be a function of the pile inclination relative to the towed array. Greater seafloor interaction of the sound radiated from the A1 leg resulted in greater time dispersion in the received signal.

Independent of the orientation of the pile, the rise and decay times and the pulse duration of the signals recorded from both legs increased with range as measured by the towed array. The energy in the pulse spreads over time as the signal propagates further in range. These dispersion effects are expected when a broadband acoustic signal is propagated in a shallow water environment (Potty et al., 2000; Potty et al., 2003). Bailey et al. (2010) noted the same trend where there was a decrease in sound level and an increase in pulse duration with increasing distance from the piling.

The pulse duration for each of the signals represented in Fig. 9 was plotted versus the measured SEL (bottom plot in Fig. 10). The signals were consistently more spread in time for the piling of leg A1 than for leg A2 based on the propagation paths of the radiated energy. This relationship supports the trend seen in the rise and decay time measurements in that the signal becomes more dispersed for higher incident angle propagation.

The top plot in Fig. 10 shows a similar relationship between the pulse duration and SEL as measured on the 

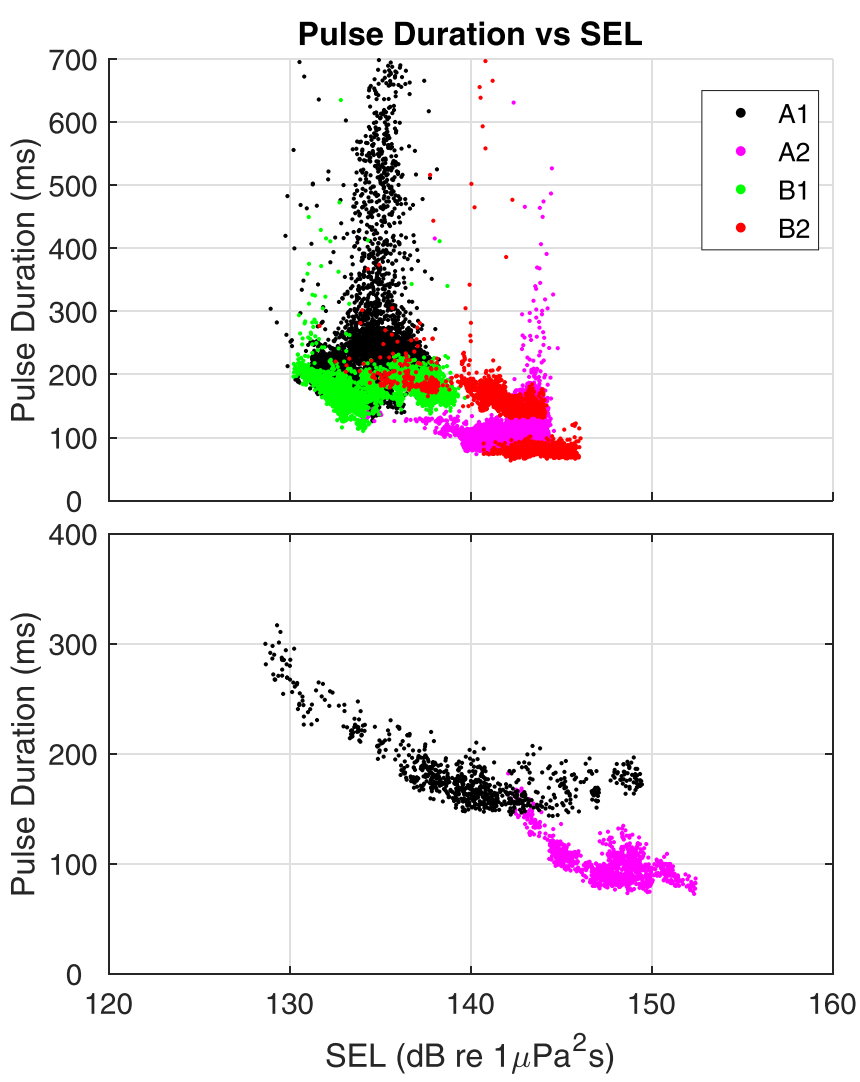

FIG. 10. (Color online) Pulse duration versus the measured SEL for each hammer strike recorded on the VLAs (top) and towed array (bottom). The length of the pulse for the piling of leg A1 is consistently longer than that for leg A2, thought to be due to the orientation of the leg.

vertical line array at $7.5 \mathrm{~km}$ for the same piling events seen in Fig. 5. The pulse duration of the signals received from the $\mathrm{A} 1$ and B1 legs is around $200 \mathrm{~ms}$ and the received SELs are lower, whereas the pulse duration is around $100 \mathrm{~ms}$ with higher received SELs for the A2 and B2 legs. When the radiated sound is directed into the seafloor the signal experiences greater dispersion and attenuation as it propagates out to $7.5 \mathrm{~km}$, which results in the received signal energy being spread over a longer time and the received sound pressure amplitude being lower. The higher dispersion is a function of increased seafloor interaction that is due to the steeper incident angle of the acoustic wave experienced with the A1 and B1 legs.

\section{Kurtosis}

The kurtosis of the recorded signals from the stationary and towed measurement systems was calculated using a one-second time window around each individual hammer strike. The kurtosis calculated on the 7.5 and $15 \mathrm{~km}$ stationary array data was similar at both ranges with the average values calculated from the four legs shown in Table I. The kurtosis was slightly lower for the signals from legs A1 and $\mathrm{B} 1$ as compared to $\mathrm{A} 2$ and $\mathrm{B} 2$.

This difference in kurtosis between legs was also seen in the towed array data shown in Fig. 11. The higher kurtosis for the A2 leg, in combination with the higher received
TABLE I. Average kurtosis calculated from the hammer strikes related to the piling of each leg recorded on a single channel from the 7.5 and $15 \mathrm{~km}$ stationary arrays.

\begin{tabular}{lcc}
\hline \hline Foundation Leg & Kurtosis at $7.5 \mathrm{~km}$ & Kurtosis at $15 \mathrm{~km}$ \\
\hline A1 & 21.7 & 20.7 \\
A2 & 35.6 & 34.1 \\
B1 & 23.9 & 22.3 \\
B2 & 31.8 & 26.3 \\
\hline \hline
\end{tabular}

sound levels and shorter pulse duration, implies that the signals from this leg were more impulsive as compared to those from leg A1. All of these factors can be related to the inclination of the pile relative to the receiver, where the A2 leg oriented away from the receiver experiences less bottom interaction and time dispersion in the propagated signal. The seafloor interaction is greater for the A1 leg and results in a signal with a lower kurtosis and received sound level and a longer pulse duration, which would describe a less impulsive signal.

The goal of this analysis was to use kurtosis to characterize the impulsiveness of the signal and determine if there was a range at which the signal could be classified as nonimpulsive based on this metric. No clear transition range or threshold were seen in the data presented in Fig. 11. In order to define a range at which the signal transitions, a threshold would need to be defined below which a signal could be considered non-impulsive. Without a clear threshold against which to compare, the measurements in Fig. 11 show that the signals from leg A2 have higher kurtosis and could be considered more impulsive relative to the signals received from leg A1 over the same range.

\section{DISCUSSION}

The sound radiation from the raked BIWF piles was modeled to validate the underlying physics influencing the trends in the measured data. The modeled results were compared to the measurements from the towed array to explain the azimuthally dependent variations observed in the data. A detailed model-data comparison was not performed due to insufficient detail of the hammer parameters to inform the modeled source forcing function. Pile driving analyzer (PDA) measurements would normally be used to validate the source force function used in modeling but were not available for the BIWF project. This detailed comparison could be undertaken as part of a future modeling effort but was not the focus of the study presented in this paper.

The BIWF piles were modeled using an equivalent inclined vertical array numerical modeling approach. In this model the near-field Green's function was calculated using an axisymmetric FEM model of a vertical pile. The Green's function in the context of this modeling is the complex sound pressure field versus frequency, depth, and range that results from a unit-amplitude harmonic force applied to the top of a modeled pile (Wilkes and Gavrilov, 2017). The FEM modeled the Green's function at a reference distance 


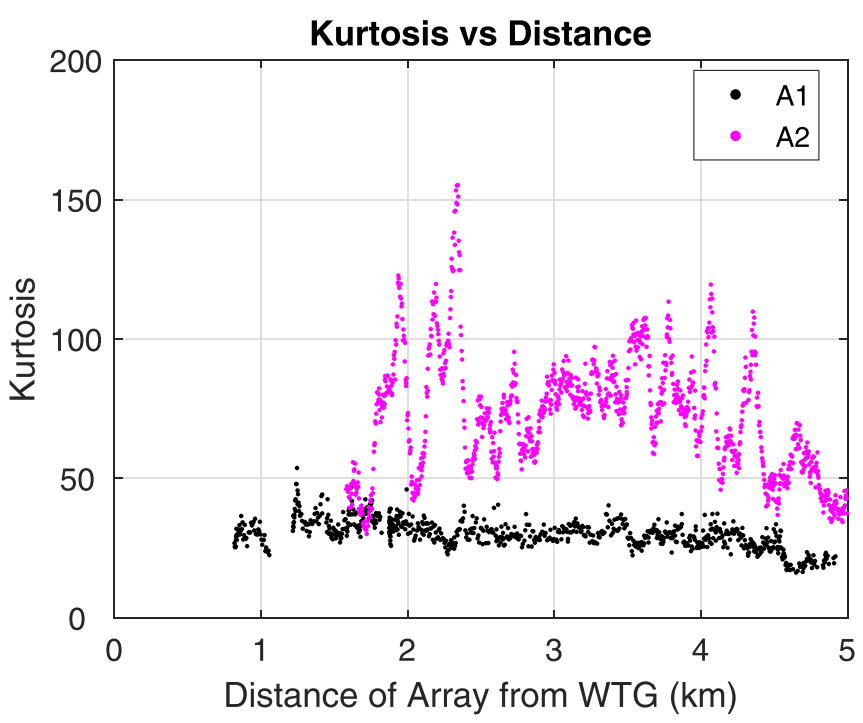

FIG. 11. (Color online) Kurtosis versus distance calculated over a onesecond time window around each individual hammer strike recorded on the towed array.

of about $6 \mathrm{~m}$ from the pile, which was simulated by a line array of point sources placed along the axis of the vertical pile, as detailed in Wilkes and Gavrilov (2017). The vertical array consisted of 100 equidistant spaced point sources placed along the array axis from $0.19 \mathrm{~m}$ below the sea surface to $37.81 \mathrm{~m}$ near the pile foot, with $0.38 \mathrm{~m}$ spacing. To represent a raked pile, the vertical line array was rotated by the angle of pile incline to align the axis of the modeled array with that of the raked pile. The sound field was then propagated into the sediment and water column using a wavenumber integration underwater sound propagation model (Jensen et al., 2011). The modeling approach is described in more detail in Wilkes and Gavrilov (2017).

The pile configuration and environmental characteristics of the BIWF study area (Table II) were used as inputs to calculate the Green's function. All other modeling parameters of the raked-pile configuration used to represent BIWF were the same as those described in Wilkes and Gavrilov (2017). The steel pile density, Young's modulus, and Poisson's ratio, along with the sand seabed and water column density as well as the sound speed were consistent with that in the referenced paper.

One half of the space surrounding the pile was modeled due to the symmetry of the pile orientation in the water column and seabed. This resulted in seven azimuth angles between $0^{\circ}$ and $180^{\circ}$ being modeled in $30^{\circ}$ increments. The

TABLE II. Input parameters used in the numerical modeling approach to describe the BIWF scenario.

\begin{tabular}{lccc}
\hline \hline Pile parameters & Length & $\mathrm{L}$ & $62.5 \mathrm{~m}$ \\
& Diameter & $\mathrm{D}$ & $1.52 \mathrm{~m}$ \\
& Wall thickness & $\mathrm{t}$ & $44.45 \mathrm{~mm}$ \\
& Penetration depth & & $14 \mathrm{~m}$ \\
& Inclination angle & $\theta$ & $13.27^{\circ}$ \\
Environmental parameters & Water depth & $d_{w}$ & $24 \mathrm{~m}$ \\
\hline \hline
\end{tabular}

model was computed on a frequency grid from 10 to $2000 \mathrm{~Hz}$ in $1 \mathrm{~Hz}$ increments to encompass the frequency bands with the majority of the sound energy measured from BIWF. The coupling range of the sound field model to be propagated to longer ranges from the inclined vertical array was $20 \mathrm{~m}$.

The Green's function of the raked pile in the underwater sound channel was calculated at a range of $20 \mathrm{~m}$, for 200 receiver depths ranging between 0.38 and $76 \mathrm{~m}$ at increments of $0.38 \mathrm{~m}$, and for seven azimuths. The modeled azimuth of $30^{\circ}$ is in the direction of pile incline where the radiated sound is directed toward the seafloor (as measured with leg A1) as opposed to the azimuth of $150^{\circ}$, which is in the direction opposite the pile incline where the radiated sound is directed through the water column (as measured with leg A2). The magnitude of the Green's functions calculated at a range of $20 \mathrm{~m}$ for azimuths of $30^{\circ}$ and $150^{\circ}$ is shown in Fig. 12. The differences between the sound radiated along each azimuth are highlighted in the figure. The magnitude of the radiated sound is greater near the seafloor along the $30^{\circ}$ azimuth as compared to the $150^{\circ}$ azimuth.

The combined effect that the depth, frequency, and azimuth dependent differences have on the propagation of the pile driving signal over range was investigated by utilizing the ORCA normal mode model (Westwood et al., 1996). This algorithm was used to propagate the Green's function

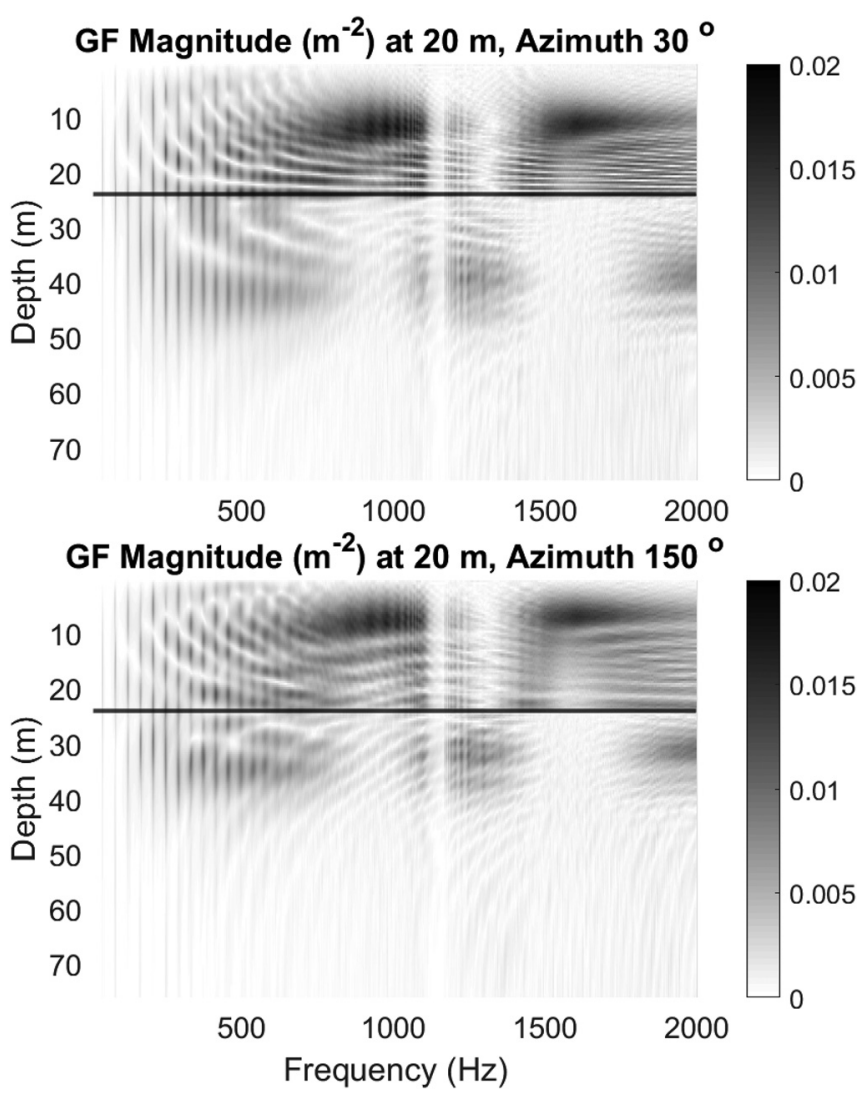

FIG. 12. Modeled Green's function (GF) magnitude at $20 \mathrm{~m}$ range from the raked pile at azimuths of $30^{\circ}$ (top) and $150^{\circ}$ (bottom) to correspond to the azimuths of the towed array transects during the leg A1 and A2 pile driving events, respectively. The line at a depth of 24 meters represents the modeled seafloor. 
estimated at $20 \mathrm{~m}$ out to a range of $3 \mathrm{~km}$. The modeled SEL was similar along the two azimuths out to a range of around $300 \mathrm{~m}$, after which the SEL along the $150^{\circ}$ azimuth (radiated sound directed through water column) was greater than that along the $30^{\circ}$ azimuth (radiated sound directed at seafloor) (Fig. 13).

The modeled sound fields were compared to the measurements from the towed array to validate the fall-off and azimuthal discrepancies observed in the data. The measured data were adjusted to remove the effect of strike energy as described in Sec. III B. Modeled SEL at azimuths of $30^{\circ}$ and $150^{\circ}$ at a depth of $12 \mathrm{~m}$, which corresponds to the depth of the towed array, were compared to the adjusted measured SEL during the piling events. The modeled and adjusted measured values were normalized to highlight the differences in levels along the two azimuths (Fig. 13).

The model results predict azimuthal differences in the resulting sound field from the piling of a raked pile. These differences increase to more than $10 \mathrm{~dB}$ as the range increases due to the vertical directionality of the sound source at different azimuth angles. A detailed comparison of the model results to the measured levels will be undertaken as a further study.

\section{CONCLUSIONS}

The dominant factor influencing the received sound levels from the installation of raked piles via impact pile driving was the inclination of the pile being driven relative to the receiver. The jacket foundation at BIWF required piles to be driven on an angle of $13.27^{\circ}$, and the received sound levels and measured signal characteristics exhibited azimuthal dependence. The rake of the pile directed the radiated sound toward the seafloor in the direction of the pile incline (as with legs A1 and B1) and near horizontally in the

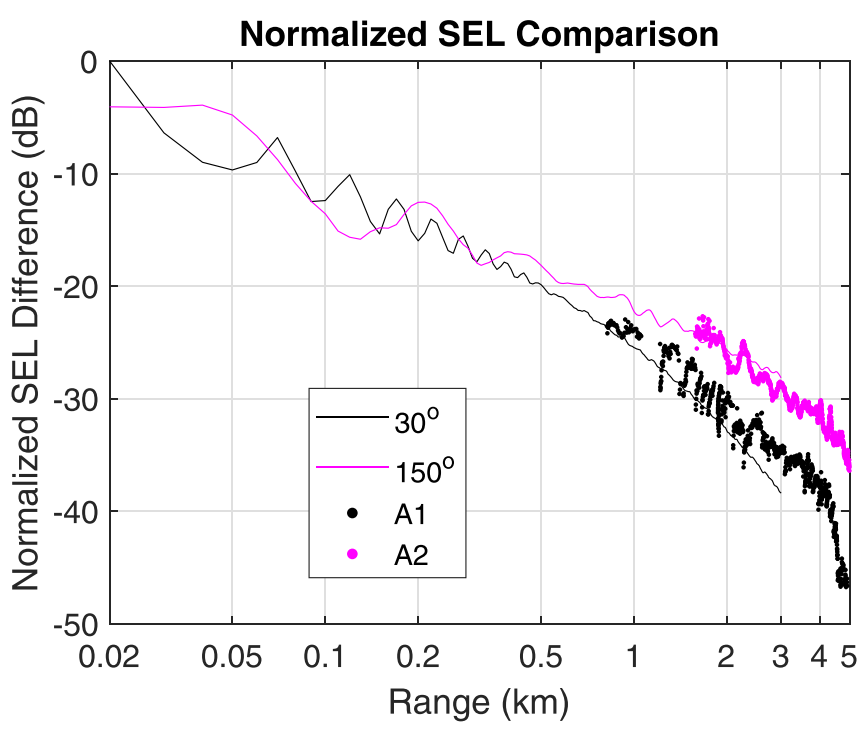

FIG. 13. (Color online) Comparison between the measured data (adjusted for strike energy and normalized) on the towed array and the normalized modeled data along the $30^{\circ}$ and $150^{\circ}$ azimuths. Differences in SEL of approximately $10 \mathrm{~dB}$ are observed at a range of $3 \mathrm{~km}$. direction opposite the pile incline (as with legs A2 and B2). The azimuthal discrepancy observed in the measurements collected at BIWF was due to the raked piles in the foundation.

Sound levels differences of 5-10 dB were observed for piles inclined in opposite directions. The magnitude and trend of the azimuthal discrepancies in sound level were explained with the model results. More detailed modeling and comparison to measured results will be a focus of further study.

The kurtosis demonstrated that the signals received along azimuths in the direction of pile incline were less impulsive than the signals received along the azimuths opposite the pile incline. This was consistent with the rise and decay time and pulse duration of the signals being longer when the energy was radiated more toward the seafloor as opposed to through the water column. The kurtosis decreased, while the rise time, decay time, and pulse duration increased with range from the piling activity as the signal became more dispersed and less impulsive. Additional analysis is needed to determine which metrics and thresholds most reliably describe when a signal transitions from being considered impulsive to non-impulsive. This information would be beneficial when assessing sound exposure on marine animals and determining the best exposure criteria to use.

The azimuthal variability in the sound field is an important factor to consider for noise mitigation and environmental assessments that are performed for raked pile installations. Environmental assessments determine the range to different acoustic thresholds enforced by federal regulations. The azimuthally dependent sound fields from a raked pile installation will impact those ranges. This will result in the mitigation range being larger along azimuths closer to $180^{\circ}$ as opposed to those along azimuths closer to $0^{\circ}$ measured along the pile axis relative to a receiver.

\section{ACKNOWLEDGMENTS}

This paper was presented at the fifth International Meeting on The Effects of Noise on Aquatic Life held in Den Haag, July 2019. Study concept, oversight, and funding for the experiment were provided by the U.S. Department of the Interior, Bureau of Ocean Energy Management (BOEM), Environmental Studies Program, Washington, DC, under Contract No. M15PC00002, Task Order M16PD00025. Collaborators in this project include Randy Gallien and Anwar Khan (HDR, Inc.).

Bailey, H., Senior, B., Simmons, D., Rusin, J., Picken, G., and Thompson, P. M. (2010). "Assessing underwater noise levels during pile-driving at an offshore windfarm and its potential effects on marine mammals," Mar. Pollut. Bull. 60(6), 888-897.

Dahl, P. H., and Dall'Osto, D. R. (2017). "On the underwater sound field from impact pile driving: Arrival structure, precursor arrivals, and energy streamlines," J. Acoust. Soc. Am. 142(2), 1141-1155.

Dahl, P. H., and Reinhall, P. G. (2013). "Beam forming of the underwater sound field from impact pile driving," J. Acoust. Soc. Am. 134(1), EL1-EL6. 
De Jong, C., and Ainslie, M. A. (2008). "Underwater radiated noise due to the piling for the Q7 Offshore Wind Park," J. Acoust. Soc. Am. 123(5), 2987.

Erdreich, J. (1986). "A distribution based definition of impulse noise," J. Acoust. Soc. Am. 79(4), 990-998.

Göttsche, K. M., Steinhagen, U., and Juhl, P. M. (2015). "Numerical evaluation of pile vibration and noise emission during offshore pile driving," Appl. Acoust. 99, 51-59.

Hamernik, R. P., Qiu, W., and Davis, B. (2003). "The effects of the amplitude distribution of equal energy exposures on noise-induced hearing loss: The kurtosis metric," J. Acoust. Soc. Am. 114(1), 386-395.

Hastie, G., Merchant, N. D., Götz, T., Russell, D. J. F., Thompson, P., and Janik, V. M. (2019). "Effects of impulsive noise on marine mammals: Investigating range dependent risk," Ecol. Appl. 29(5), e01906.

HDR (2018). "Field observations during wind turbine foundation installation at the Block Island Wind Farm, Rhode Island. Appendix D: Underwater Sound Monitoring Reports," BOEM 2018-029 (U.S. Department of the Interior, Washington, DC).

Henderson, D., and Hamernik, R. P. (1986). "Impulse noise: Critical review," J. Acoust. Soc. Am. 80(2), 569-584.

ISO 10843 Acoustics (1997). "Methods for the description and physical measurement of single impulses or series of impulses" (International Organization for Standardization, Geneva, Switzerland).

ISO 18405 Underwater Acoustics (2017a). "Terminology" (International Organization for Standardization, Geneva, Switzerland).

ISO 18406 (2017b). "Underwater acoustics measurement of radiated underwater sound from percussive pile driving" (International Organization for Standardization, Geneva, Switzerland).

Jensen, F. B., Kuperman, W. A., Porter, M. B., and Schmidt, H. (2011). Computational Ocean Acoustics, 2nd ed. (Springer Science, New York), pp. 233-529.

Kastelein, R. A., Helder-Hoek, L., Van de Voorde, S., von BendaBeckmann, A. M., Lam, F.-P. A., Jansen, E., de Jong, C. A. F., and Ainslie, M. A. (2017). "Temporary hearing threshold shift in a harbor porpoise (Phocoena phocoena) after exposure to multiple airgun sounds," J. Acoust. Soc. Am. 142(4), 2430-2442.

Kim, H., Miller, J. H., and Potty, G. R. (2013). "Predicting underwater radiated noise levels due to the first offshore wind turbine installation in the U.S.," J. Acoust. Soc. Am. 19, 040067.

Laughlin, J. (2005). "Underwater sound levels associated with pile driving on the Sr 24, I-82 to keys road project Yakima River" (Washington State Department of Transportation, Seattle).

Lei, S., Ahroon, W. A., and Hamernik, R. P. (1994). "The application of frequency and time domain kurtosis to the assessment of hazardous noise exposures," J. Acoust. Soc. Am. 95(5), 3005.

Lin, Y.-T., Newhall, A. E., Miller, J. H., Potty, G. R., and Vigness-Raposa, K. J. (2019). "A three-dimensional underwater sound propagation model for offshore wind farm noise prediction," J. Acoust. Soc. Am. 145(5), EL335-EL340.

MacGillivray, A. (2018). "Underwater noise from pile driving of conductor casing at a deep-water oil platform," J. Acoust. Soc. Am. 143(1), $450-459$.

Martin, S. B. (2019). "One minute at a time: Advancing our ability to estimate effects of man-made sound on marine life," Ph.D. thesis, Dalhousie University Halifax, Nova Scotia.

Martin, S. B., and Barclay, D. R. (2019). "Determining the dependence of marine pile driving sound levels on strike energy, pile penetration, and propagation effects using a linear mixed model based on damped cylindrical spreading," J. Acoust. Soc. Am. 146, 109-121.
National Marine Fisheries Service (2018). "2018 revision to technical guidance for assessing the effects of anthropogenic sound on marine mammal hearing (version 2.0): Underwater thresholds for onset of permanent and temporary threshold shifts," NOAA Technical Memorandum NMFSOPR-59.

National Marine Fisheries Service (2015). "DRAFT guidance for assessing the effects of anthropogenic sound on marine mammal hearing," Document No. 2016-05886. (Federal Registrar, Washington, DC).

Norro, A. M. J., Rumes, B., and Degraer, S. J. (2013). "Differentiating between underwater construction noise of monopile and jacket foundations for offshore windmills: A case study from the Belgian Part of the North Sea," Sci. World J. 2013, 897624

Popper, A. N., Carlson, T. J., Hawkins, A. D., Southall, B. L., and Gentry, R. L. (2006). "Interim criteria for injury of fish exposed to pile driving operations: A white paper," 1-15, available at https:/www.nrc.gov/docs/ ML0932/ML093210627.pdf.

Popper, A. N., Hawkins, A. D., Fay, R. R., Mann, D. A., Bartol, S., Carlson, T. J., Coombs, S., Ellison, W. T., Gentry, R. L., Halvorsen, M. B., Løkkeborg, S., Rogers, P. H., Southall, B. L., Zeddies, D. G., and Tavolga, W. N. (2014). Sound Exposure Guidelines for Fishes and Sea Turtles: A Technical Report Prepared by ANSI-Accredited Standards Committee S3/SC1 and Registered with ANSI. ASA S3/SC1.4 TR-2014 (Springer International Publishing, Cham, Switzerland).

Potty, G. R., Miller, J. H., and Lynch, J. F. (2003). "Inversion for sediment geoacoustic properties at the New England Bight," J. Acoust. Soc. Am. 114(4), 1874-1887.

Potty, G. R., Miller, J. H., Lynch, J. F., and Smith, K. B. (2000) "Tomographic inversion for sediment parameters in shallow water," J. Acoust. Soc. Am. 108(3), 973-986.

Reinhall, P. G., and Dahl, P. H. (2011). "Underwater Mach wave radiation from impact pile driving: Theory and observation," J. Acoust. Soc. Am. 130(3), 1209-1216.

Robinson, S. P., Theobald, P. D., and Lepper, P. A. (2012). "Underwater noise generated from marine piling," J. Acoust. Soc. Am. 17, 070080.

Southall, B. L., Bowles, A. E., Ellison, W. T., Finneran, J. J., Gentry, R. L., Greene, C. R., Jr., Kastak, D., Ketten, D. R., Miller, J. H., Nachtigall, P. E., Richardson, W. J., Tomas, J. A., and Tyack, P. L. (2007). "Marine mammal noise exposure criteria: Initial scientific recommendations," Aquat. Mamm. 33(4). 1-121.

Southall, B. L., Finneran, J. J., Reichmuth, C., Nachtigall, P. E., Ketten, D. R., Bowles, A. E., Ellison, W. T., Nowacek, D. P., and Tyack, P. L. (2019). "Marine mammal noise exposure criteria: Updated scientific recommendations for residual hearing effects," Aquat. Mamm. 45(2), $125-232$.

Tetra Tech (2012). "Block Island Wind Farm and Block Island transmission system environmental report: Construction and operations plan" (Deepwater Wind, Providence, RI).

Tetra Tech, and JASCO (2015). "Hydroacoustic monitoring program final technical report Block Island wind farm construction 2015," (Deepwater Wind, Providence, RI).

Westwood, E. K., Tindle, C. T., and Chapman, N. R. (1996). "A normal mode model for acousto-elastic ocean environments," J. Acoust. Soc. Am. 100(6), 3631-3645.

Wilkes, D. R., and Gavrilov, A. N. (2017). "Sound radiation from impactdriven raked piles," J. Acoust. Soc. Am. 142(1), 1-11.

Zampolli, M., Nijhof, M. J. J., de Jong, C. A. F., Ainslie, M. A., Jansen, E. H. W., and Quesson, B. A. J. (2013). "Validation of finite element computations for the quantitative prediction of underwater noise from impact pile driving," J. Acoust. Soc. Am. 133(1), 72-81. 